\title{
LANGUAGE EVOLUTION AND THE EMERGENCE OF CONSTRUCTIONS IN INTERACTION
}

\author{
MICHAEL PLEYER \\ mpleyer@uni-koblenz.de \\ English Department, Universität Koblenz-Landau, Campus Koblenz, Koblenz, Germany
}

This talk explores the evolution of language from the perspective of dialogic construction grammar, dialogic syntax, emergent grammar and interactional usage-based approaches (Goldberg 2006; Du Bois 2014; Hopper 2015, Brône \& Zima 2014; Pleyer 2017). These approaches all focus on "the emergence of grammatical patterning in on-line production, dialogically, and as a cooperative achievement" (Fried \& Östman 2005: 1756). This talk argues that investigations of the evolutionary emergence of grammatical structure and constructions need to pay attention to this focus on the online, in-vivo interactional emergence of constructions and their subsequent conventionalization.

As I argue, this process of interactive constructionalization also presents a way how the first protoconstructions could have emerged in protolinguistic hominin communities.

In interaction, cognitive processes such as priming, conceptual pacts, intersubjective alignment, local schematization and routinization, microentrenchment and resonance activation can lead to the emergence of a temporary local network of constructions (Brône \& Zima 2014). In the case of frequently recurring routines and practices, ad hoc constructions that are frequently microentrenched also acquire increasing degrees of entrenchment and conventionalization. Over time, this leads to these constructions emerging more easily and more frequently in interactions. This in turn subsequently leads to them becoming fully entrenched and acquire that status of grammaticalized and conventionalized constructions, or protoconstructions, proper. This is in line with the usage-based approach, which sees linguistic constructions as abstractions from frequently reoccurring instances of language - or in this case protolanguage - in interaction (Pleyer 2017). 
It is therefore argued that the first conventionalized and community-wide protoconstructions are the result of frequently recurring processes of the interactive co-construction of online protoconstructional templates. These were then subject to conventionalization and entrenchment processes (Schmid 2017). The account presented here therefore assumes that ad hoc, temporary protoconstructios emerged first, and then subsequently and over time evolved into more conventionalized and entrenched protoconstructions. These in turn evolved into construction proper through processes of grammaticalization and constructionalization (Heine \& Kuteva 2007; Traugott \& Trousdale 2013). In this way, temporary, emergent communicative routines turned into an inventory of entrenched community-wide communicative routines - protolanguage -, which then evolved into a fully grammaticalized and conventionalized structured inventory of constructions shared by a community - language. Crucially, these early, temporary, emergent protoconstructional templates should not be seen as form-meaning pairings in the same way as human constructions. Instead, they are more like form-meaning potential pairings in which communicative routines still have a high-degree of semantic ambiguity and openness. In order to function as communicative units within an interaction, they are still heavily reliant on context. This semantic openness, or underspecification, would also characterize community-wide protoconstructional inventories. This view is consistent with analyses of the gesture systems of non-human primates, whose meaning and function is heavily context-dependent and underspecified (Liebal et al. 2014; Moore 2014). The gesture systems of non-human primates and the protoconstructional inventory possessed by early humans are therefore theorized to share many similarities. However, the human protoconstructicon would have been much more semantically and expressively powerful, as they were based on much more powerful capacities for metacognition, advanced sociocognitive capacities and perspective-taking (Scott-Phillips 2015, Tomasello 2008). In addition, early humans likely also possessed a "massive storage" capacity for a bigger protoconstructional inventory than is found in non-human primates (Hurford 2012; Pleyer \& Lindner 2014).

They also likely possessed more sophisticated symbolization and schematization skills, which aided in the abstraction and generalization of protoconstructions into constructions proper (Penn et al. 2008; Deacon 1997; Thompson et al. 1997).

As this outline shows, then, dialogic and interactive approaches to the emergence of structure have much to offer for language evolution research (Pleyer 2017). 


\section{References}

Brône, G., \& Zima, E. (2014). Towards a dialogic construction grammar: Ad hoc routines and resonance activation. Cognitive Linguistics, 25(3), 457 495. doi:10.1515/cog-2014-0027

Deacon, T. W. (1997). The Symbolic Species: The Co-Evolution of Language and the Brain. New York: Norton.

Du Bois, J. W. (2014). Towards a dialogic syntax. Cognitive Linguistics, 25(3), 359-410.

Fried, M., \& Östman, J.-O. (2005). Construction Grammar and spoken interaction: the case of pragmatic particles. Journal of Pragmatics, 37(11), 1752-1778.

Goldberg, A. E. (2006). Constructions at Work: The Nature of Generalization in Language. Oxford ; New York: Oxford University Press.

Heine, B., \& Kuteva, T. (2007). The Genesis of Grammar: A Reconstruction. Oxford: Oxford University Press.

Hopper, P. J. (2015). An Emergentist Approach to Grammar. In B. MacWhinney \& W. O'Grady (Eds.), The Handbook of Language Emergence (pp. 314-327). Malden, MA: Wiley Blackwell.

Hurford, J. R. (2012). The Origins of Grammar: Language in the Light of Evolution II. Oxford: Oxford University Press.

Liebal, K., Waller, B. M., Burrows, A. M., \& Slocombe, K. E. (2014). Primate Communication: A Multimodal Approach. Cambridge: Cambridge University Press.

Moore, R. (2014). Ape Gestures: Interpreting Chimpanzee and Bonobo Minds. Current Biology, 24(14), R645-R647. doi:http://dx.doi.org/10.1016/j.cub.2014.05.072

Penn, D. C., Keith J. Holyoak and Daniel J. Povinelli. (2008). Darwin's mistake: Explaining the discontinuity between human and nonhuman minds. Behavioral and Brain Sciences, 31(2), 109-130.

Pleyer, M. (2017). Protolanguage and mechanisms of meaning construal in interaction. Language Sciences, 63, 69-90. doi:https://doi.org/10.1016/j.langsci.2017.01.003

Pleyer, M., \& Lindner, N. (2014). Constructions, Construal and Cooperation in the Evolution of Language. In E. A. Cartmill, S. Roberts, H. Lyn, \& H. Cornish (Eds.), The Evolution of Language. Proceedings of the 10th Conference (pp. 244-251). Singapore: World Scientific.

Schmid, H.-J. ,ed. (2017). Entrenchment and the Psychology of Language Learning: How We Reorganize and Adapt Linguistic Knowledge. Washington, DC: American Psychological Association.

Scott-Phillips, T. C. (2015). Speaking our Minds: Why Human Communication is Different, and How Language Evolved to Make it Special. Houndmills: Palgrave Macmillan. 
Thompson, R. K. R., Oden, D. L., \& Boysen, S. T. (1997). Language-naïve chimpanzees (Pan troglodytes) judge relations between relations in a conceptual matching-to-sample task. Journal of Experimental Psychology: Animal Behavior Processes, 23, 31-43.

Traugott, E. C., \& Trousdale, G. (2013). Constructionalization and Constructional Changes. Oxford: Oxford University Press. 